\title{
Techniques to Avoid Shifting to the Mother Tongue When Teaching Using EFL as the Language of Instruction
}

\author{
Bagas Prayogo Utomo \& Tono Suwartono \\ Universitas Muhammadiyah Purwokerto, Indonesia \\ (bagaspu@gmail.com)
}

\begin{abstract}
Learning other languages is not just an act of translating ideas into the target language, but it is a process of learning the whole set of the language itself. In the context of teaching English as Foreign Language, teachers take a very crucial role. They should be able to set such setting where their students can be exposed into English environment as much as possible. On the other hand, maintaining the use English at all time is a difficult task to do, since the vocabulary which is already mastered by the foreign learners, often, is very limited. Meanwhile, in the process of learning and acquiring new language, vocabulary itself plays a quite fundamental part. It creates a challenge for the teacher, in terms of making the students comprehend a certain word that they do not understand previously. Shifting into the mother tongue is surely the easiest escape when a teacher encounters such problem. However, teachers, as educators, should be creative enough to find alternatives that allow the students to learn new words while the use of English is maintained during the class. This article enlists several techniques which a teacher can apply in teaching to provide elucidation of new vocabulary to the students, without having to shift into the mother tongue.
\end{abstract}

Keywords: technique; language teaching; language shifting; EFL; mother tongue.

The importance of English as an international language in the global context is no longer needed to be questioned. As a result, teachers have been playing important roles in teaching English, especially, for foreign languaeg learners. The major drawback for learners in learning English as a foreign language is that the language, often, is only learned and practiced in the classroom. Long in Polio and Duff (1994) stated what transpires in the classroom is, arguably, even more critical for foreign learners because the classroom is often the learners' sole source of foreign language input (and output). In addition, Mattarima (2011) stated that the problems which Indonesian EFL learners face in developing their performance relate not only to their linguistic and personality factors, but also the types of classroom tasks provided by the teachers. Further, he 
mentioned that teachers still frequently use Indonesian language (mother tongue) to discuss the topic and, to some extent, to explain the grammatical rules of the Target Language. The use of mother tongue in teaching foreign language is inevitable and, in some cases, necessary. However, shifting to the mother tongue will reduce the amount of exposure of English that the students should get during the learning process. Turnbull (2001) highlighted the drawbacks to teachers' extensive reliance on mother tongue and called for an optimal, or acceptable, amount of both target language and mother tongue in foreign language classrooms.

It is essential for teachers to maintain the use of English during the teaching process, not only because the students need all the exposure of English that they can possibly get, but also for the sake of agreement that learning a foreign language is not merely an act of translating words. Shifting or translating a word to the mother tongue indicates the teacher's incapability in maintaining the use of English during the class. A teacher should be creative enough to find alternatives in order to make the students understand of certain words without shifting into other languages. Hence, the question is: what are the techniques which a teacher can use to avoid shifting to the mother tongue when teaching using English as Foreign Language? This article will enlist and offer several techniques that a teacher, who plays the important role in foreign language classroom, can adopt and apply so that he or she does not necessarily have to shift to the mother tongue when problems, like difficulty in comprehending new vocabulary, are encountered by learners. Therefore, the maximum amount of foreign language exposure can be achieved.

\section{Techniques to Avoid Language Shifting}

Shifting to the mother tongue when the students do not understand the words the teacher just said is the easiest and most efficient strategy. Translating the words in either the utterance or sentence will make them understand the idea it conveys instantly. However, retaining the use of English when a teacher faces such problem is not an impossible thing to do. Using the right techniques, a teacher would be able to keep teaching using English without sacrificing the students' right to be within English environment as much as possible, during the class.

\section{Option-Based Tasks}

Option-based task is one of the techniques in which the teacher provides the students exercises in order to assess their English competence. The use of this technique is limited for assessment, but it is quite easy to conduct, and the students' results are also measured easily. Optionbased tasks take several forms of exercises, such as multiple choice and matching. The following paragprahs will describe the forms of exercises in details.

\section{Multiple Choice}

To help the students understand the meaning, a vocabulary development through multiple choice exercises is an alternative technique to avoid shifting to mother tongue, which means communicativeness is maintained, linguistic input/exposure is supported, and students are made to stay tuned (Suwartono, 2019). Even though this technique is limited only for assessment, it is still effective to build the students' vocabulary. Furthermore, this technique can be applied through various types of task. The teacher may provide the students exercise by asking the synonym or antonym of a particular word. The teacher can even provide gap-filling sentences and ask the students to choose the most possible word to fill the sentence from the options given.

\section{1) Synonym for Multiple Choice Task \\ Synonym is a word having the same or nearly the same meaning as another in the language. Providing the students a synonym-themed task will enrich the}


students' vocabulary capacity.

For example:

Anna, close the door, please!

Instruction:

Chose a word from the options below which has the closest meaning with the word typed in italic.
a. shut
b. open
c. clean
d. wipe

2) Antonym for Multiple Choice Task

The opposite of synonym, antonym is a word having the opposite meaning as another in the language. Providing the students an antonym-themed task will enrich the students' vocabulary capacity.

For example:

Anna, close the door, please!

Instruction:

Chose a word from the options below which has the opposite meaning with the word typed in italic.
a. shut
b. open
c. clean
d. wipe

3) Gap-filling Sentence for Multiple Choice Task

Providing a gap-filling sentence in multiple choice task will enforce the students to find the most suitable word to fill in the gap. Using this technique, the students have to find the most appropriate word to fill in the gap by considering the context of the sentence.

For example:

Teacher: "Dianne, can you ... the whiteboard for me, please?"

Instruction:

Choose the most suitable word to fill the blank space.
a. shut
b. open
c. sell
d. wipe

Matching

As far as vocabulary building is concerned, it is a very good idea to use matching exercises. In its appearance, this technique looks like a puzzle; and therefore, attractive (Suwartono, 2019). Using this technique, the students draw lines that match the contents between two columns. The contents put in each column could be various. Students may match word-word, word-picture, or word-sentence.

For example:

Instruction: Match the word in the left side with the appropriate sentence in the right side!

\begin{tabular}{|c|c|}
\hline Watch & me move these chairs. \\
\hline Help & $\begin{array}{l}\text { this video carefully, } \\
\text { then write a response. }\end{array}$ \\
\hline Clean & $\begin{array}{l}\text { your hands if you are } \\
\text { done with the glue. }\end{array}$ \\
\hline Wash & $\begin{array}{l}\text { the desk, I need some } \\
\text { space. }\end{array}$ \\
\hline Open & $\begin{array}{l}\text { the door, it's getting a } \\
\text { bit hot here. }\end{array}$ \\
\hline
\end{tabular}

\section{Pauses}

Pauses are useful for the speaker (Goldman-Eisler, 1968) and for the listener (Aaronson, 1968). There is a positive correlation between the need for pause time during the speech sequence and the level of processing required by the task. Appropriate pauses will give the audience more time to process the incoming information. There are three types of pauses as stated by Igras-Cybulska (2016), namely silent, filled, and breath pauses.

The most intuitive is silent pauses, as regions of signal where no voice activity is recorded. The second types are filled pauses that do not affect sentence meaning, like eee, $\mathrm{hmm}, \mathrm{mmm}$, but perturb utterance fluency. They can appear even $10-20$ per minute in case of inexperienced speakers. The third sort of pauses is breath pauses. In case of normal physiological condition, the value of breath per minute is $12-20$ while resting, and as prior work showed, it is 10-12 during speech production.

In accordance with the previous exposition, Igras-Cybulska (2016) marked out: (1) regular natural pauses caused by respiration 
activity (breath pauses), (2) irregular intentional pauses, purposely used as a stylistic form, especially by professional speakers (silent pauses), and (3) irregular, unintentional disfluencies, effects of uncertainty, hesitations or short reflections (filled pauses). Therefore, it is advisable for teachers to employ silent pauses or breath pauses during teaching, since filled pauses indicate a sign of hesitation, instead. The use of appropriate pauses is proved to help the students understand the ideas being transferred since pauses give the students more time to process them.

\section{Speed Reduction}

Hayati (2010) stated that slow rate of speech gives the students enough time to process the stream of information at a slower rate of delivery. This technique eliminates the chance of linking sound to occur, and it gives the audience longer time to process the words that they just heard. If the students fail to comprehend the words that a teacher just stated, a simple solution like reducing the speed can possibly help. In normal speed, the students would probably hear "Couldja read tha' line, Jon?", while in reduced speed, a clearer utterance like "Could you read that line, Jon?" is generated.

\section{Rephrasing}

There are several ways to create a sentence that express the idea of giving instruction. Different words may represent the same idea. This fact would come in handy if a teacher faces a problem that require different word when students fail to understand the previous one. Rephrasing can simply defined as action of saying or writing something again in a different and usually clearer way. Narayan et. al. (2017) stated that rephrasing an idea can be done using paraphrases, synonyms, or alternative syntactic constructions. For instance, if the student cannot understand the instruction "Wipe the whiteboard, please!", a teacher may rephrase it into "Clean the whiteboard, please!". It will allow the students to comprehend the instruction given, and in addition, the students will learn new vocabulary.

\section{Definition}

In its simplest meaning, definition is an exact statement or description of the nature, scope, or meaning of something. Providing the description of a particular word that the students fail to comprehend, surely, take longer time than shifting to the mother tongue. However, according to Grauberg (1997), the second stage out of four stages in the process of learning vocabulary is "understanding meaning". This means understanding the information conveyed by a certain word or phrase. In the short term, this technique seems to be inconvenient to employ because a teacher should elaborate the meaning of a word in longer sentence or utterance. For the long run, on the other hand, providing the definition of, even, a single word will serve the students good, since they will learn new vocabulary, and memorize in way that will last longer than learning from simple way such as translating the vocabulary into their native language. See the illustration below of how a teacher can use this technique.

\section{illustration:}

Teacher: "Students, pay attention on the procedure text below. Read the text carefully. Raise your hand if you don't understand what you have to do."

Student: "Sir, what do I have to do in the step number five?"

Teacher: "Marinate the chicken in the marinade for an hour. Marinate means soaking something, especially food, in a marinade."

\section{Visualization}

When it comes to the problem that relates with the lack of vocabulary, providing a picture during teaching will help the students in understanding the instruction given. The effect of pictures, according to Weidenmann 
(1989), can be explained in three ways, namely, (1) pictures can attract the learner's attention, (2) pictures can help the reader to understand information that is hard to describe in verbal terms, and (3) pictures can reduce the likelihood that acquired information is forgotten, perhaps as a consequence of an additional encoding in pictorial memory. This technique can be used, but not limited, to teach instruction-related material, such as procedure text.

\section{Demonstration}

Demonstration, in this context, refers to an action of showing to the students of how something is done. According to Morgan (1976), the demonstration technique, when properly selected and used, may be very effective. It is not a universal method, still, demonstration are most likely to be successful (1) in teaching operative skills (2) in developing understandings, (3) in show how to carry out new practice, and (4) in securing the acceptance of new and improved ways of doing things.

By employing this technique, students will learn new vocabulary and strengthen their understanding of the new words by seeing what they are learning. Further, Husnu (2018) stated that demonstration technique is an interesting technique which enables the teacher to deliver materials in a simple way that is suitable for EFL learners. It creates fun class situation, avoids boring drills, and encourages the students to be enthusiastic.

Teacher of a foreign language classroom ought to be aware that shifting to the mother tongue should only be done when its functionality is crucial to help the students comprehend better. Nevertheless, when the use of the target language is able to be maintained using one of the techniques above, shifting to the mother tongue is avoidable. Therefore, students will receive more useful exposures to the target language which later will become their language input.

\section{Conclusion}

Teacher of English as a Foreign Language (EFL) deals a quite important role in class. Foreign learners of English require the exposure of English as much as they can get, since they only receive English actively during the class, so maintaining the use of English during teaching at all the time is highly advisable. However, foreign learners tend to have problem that is related with their lack of vocabulary. It creates another problem since using English during the entire teaching seems impossible to do when the students fail to comprehend a word or two that the teacher just said.

Shifting to the mother tongue seems to be the easiest solution to deal with the vocabulary-related problem. However, there are techniques which a teacher can employ when they face such problem. These techniques are: (1) option-based task which can be in the form of multiple choice or matching, (2) pauses, they allow the students to let the information to sink in before receiving a new one, (3) speed reduction, it gives the students more time to process the information, (4) rephrasing, restate the instruction using another word or different structure of sentence, (5) definition, it provides the description of a certain word, (6) visualization, it allows the students to see both text and picture, or listen to instruction and see picture at the same time, and (7) demonstration, it gives the students understanding of how something is done or achieved by showing them how to make it done. There are several techniques which can be used to substitute the need of shifting to the mother tongue in order to make the students comprehend a certain word.

Teachers, especially foreign language teachers, should be creative and able to provide, and set such atmosphere where the students can get all the exposure of English which they can get during the class. Employing one or few of the techniques provided above could come in handy when the teacher faces a problem that related with the students' lack 
of vocabulary. Eventually, teachers' language becomes students' language input, that will help them acquire the language.

\section{References}

Aaronson, D. (1968). Temporal Course of Perception in an Immediate Recall Task. J. Exp. Psychol. 76. 129-140.

Goldman-Eisler, F. (1968). Psycholinguistics: Experiments in Spontaneous Speech. New York: Academic Press.

Grauberg, Walter. (1997). The Elements of Foreign Language Teaching. Languages in Practice Vol 7. UK: Multilingual Maters.

Hayati, Abdolmajid. (2010). The Effect of Speech Rate on Listening Comprehension of EFL learners. Creative Education. 01. 10.4236/ce.2010.12016.

Husnu, Muhammad. (2018). Demonstration Technique to Improve Vocabulary and Grammar Element in Teaching Speaking at EFL Learners. English Language Teaching 11(2)

Igras-Cybulska et al. (2016). Structure of Pauses in Speech in The Context of Speaker Verification and Classification of Speech Type. Journal on Audio, Speech, and Music Processing 18. DOI 10.1186/ s13636-016-0096-7.

Mattarima, K., \& Hamdan, A. R. (2011). The Teaching Constraints of English as A Foreign Language in Indonesia: The Context of School Based Curriculum. Sosiohumanika, 4(2).

Morgan, Barton, Glenn E. Holmes, and Clarence E. Bundy. (1976). Method in Adult Education (3rd Ed). Danville: The Interstate Printers \& Publisher, Inc.

Narayan, S., Gardent, C., Cohen, S. B., \& Shimorina, A. (2017). Split and rephrase. arXiv preprint arXiv:1707.06971.
Polio, C.G. and Duff, P.A. (1994), Teachers' Language Use in University Foreign Language Classrooms: A Qualitative Analysis of English and Target Language Alternation. The Modern Language Journal, 78. 313-326. doi:10.1111/j.1540-4781.1994.tb02045.x

Suwartono, T., \& Oktavia, N. F. (2019). OptionBased Tasks: An Effort to Encourage The EFL Students to Learn. LEKSIKA, 13(1), 46-54.

Turnbull, M. (2001). There is a role for the L1 in second and foreign language teaching, but... Canadian Modern Language Review, 57, 531-540. doi:10.3138/ cmlr.57.4.531

Weidenmann, Bernd. (1989). When Good Pictures Fail: An Information-Processing Approach to the Effect of Illustrations. Advances in Psychology 58, 157-170 